\title{
Mães Ouvintes com Filhos Surdos: Concepção de Surdez e Escolha da Modalidade de Linguagem
}

\author{
Angélica Bronzatto de Paiva e Silva ${ }^{2}$ \\ Universidade Estadual de Campinas \\ Maria Cristina da Cunha Pereira \\ Universidade Católica de São Paulo \\ Maria de Lurdes Zanolli \\ Universidade Estadual de Campinas
}

\begin{abstract}
RESUMO - O objetivo foi analisar a concepção que mães ouvintes com filhos surdos têm sobre surdez e relacioná-la com a modalidade de linguagem utilizada pela mãe e pela criança. Entrevistaram-se 10 mães de crianças surdas, cinco pré-escolares e cinco escolares. Procedeu-se à análise de conteúdo das categorias "concepção de surdez" e "escolha da modalidade de linguagem". A análise dos dados evidenciou que uma das mães parece ver a surdez como doença, outra como uma diferença e as outras mães encontram-se entre as duas posições. Quanto à escolha da modalidade de linguagem, metade das mães relata que seus filhos usam predominantemente os sinais, a outra metade utiliza a fala e os sinais e uma criança usa somente a linguagem oral. A criança cuja mãe concebe a surdez como doença procura se comunicar oralmente, enquanto aquela cuja mãe vê a surdez como diferença faz uso de sinais e de fala para se comunicar.
\end{abstract}

Palavras-chave: concepção de surdez; pais de surdos; surdez e modalidades de linguagem.

\section{Hearing Mothers with Deaf Children: Conception of Deafness and Choice of Language Mode}

\begin{abstract}
The aim of this study was to analyze the conceptions that hearing mothers of deaf children have about deafness and relate it to the language mode used by the mother and the child. We interviewed 10 mothers of deaf children, five of whom were prescholars and five of school age. The content was analyzed as to thematic and category types, with emphasis on the categories "conception of deafness" and "choice of language mode". Data analysis showed that one mother seems to see deafness as a disease, another as a difference and the other mothers were found to be somewhere between these two views. In relation to the preferred language mode, half the mothers reported that their children predominantly use signs, the other half uses speech and signs, with the exception of one child who uses only speech. The child whose mother acts as if deafness is a disease uses speech while another one whose mother acts as if deafness is a difference uses speech as well as signs.
\end{abstract}

Key words: deafness; conception of deafness; parents of deaf children; deafness and language mode.

A surdez se caracteriza como um problema sensorial não visível, que acarreta dificuldades na recepção, percepção e reconhecimento de sons, ocorrendo em diferentes graus, do mais leve (que interfere na aquisição da fala, mas não impede o indivíduo de se comunicar por meio da linguagem oral), ao mais profundo (que impede o indivíduo de adquirir a linguagem oral) (Lima, 1997).

A Organização das Nações Unidas estima que 1,5\% da população mundial possui deficiência auditiva (Corde, 1996). No Brasil, dos 34,5 milhões de deficientes brasileiros, 5,7 milhões têm deficiência auditiva (IBGE, 2006), um número significativo em termos de saúde pública, uma vez que, se

1 Este artigo é parte da pesquisa de doutorado da priemira autora, intitulada "Aspectos psicossociais da surdez: a representação social dos pais", desenvolvida no Curso de Pós-Graduação em Saúde da Criança e do Adolescente da Faculdade de Ciências Médicas da UNICAMP, sob orientação da Prof ${ }^{a}$ Maria de Lurdes Zanolli

2 Endereço: Rua Tessália Vieira de Camargo, 126, Bairro Barão Geraldo, Campinas, SP, Brasil 13084-971. E-mail: arbps@ fcm.unicamp.br estas crianças não receberem um atendimento adequado e desenvolverem uma competência linguiística, terão sérios problemas para constituírem-se como sujeitos ativos, participantes de uma sociedade.

Em nossa sociedade existem padrões pré-moldados e valores culturais de normalidade; aqueles que não se ajustam recebem a rotulação de "desviante", o que os coloca na posição de propensos a receberem mais conceitos negativos do que positivos (Figueira, 1996).

Esta rotulação geralmente surge quando uma pessoa apresenta evidências de que tem um atributo que a torna diferente dos outros. No caso da surdez, o aspecto mais visível da falta de audição é a falta da linguagem oral e essa falta é realçada numa sociedade que se comunica principalmente pela fala. $\mathrm{O}$ fato de o surdo ser diferente o torna estigmatizado e, quando o seu efeito de descrédito é muito grande, algumas vezes ele também é considerado como tendo um defeito, uma fraqueza, uma desvantagem (Goffman, 1978).

A criança surda que nasce em um meio ouvinte enfrenta, desde o nascimento, uma rede de construções identificatórias, prefiguradas pelas expectativas de seus pais, os quais, é na- 
tural, desejam que ela também seja ouvinte. Dessa forma, o processo de socialização da criança surda com pais ouvintes é, muitas vezes, conflitante desde o início. O conhecimento da surdez em uma criança supõe longos processos, tanto no estabelecimento do diagnóstico, como para que os pais elaborem sua frustração e comecem a aceitar a criança diferente do imaginado. São processos extremamente complexos e interferem no modo como os pais e especialistas vão construir uma determinada imagem social do que é a surdez e do que é a criança surda (Behares, 1993).

Entre as crianças surdas, $90 \%$ têm pais ouvintes, e a ausência de experiência com perda de audição faz com que esses pais enfrentem vários obstáculos em relação ao desenvolvimento dessa criança, sendo um deles a dificuldade de comunicação (Eleweke \& Rodda, 2000). Os pais são fortemente influenciados pela informação recebida, especialmente no período que se segue ao diagnóstico da perda de audição. A forma como os pais percebem as funções do aparelho auditivo, a influência da atitude do profissional que os atendeu, bem como a qualidade do aconselhamento, influenciam a decisão dos pais em relação aos recursos comunicativos (Eleweke \& Rodda,2000).

Os pais procuram uma instituição, matriculam o filho surdo, no entanto a permanência parece depender da aceitação da proposta da instituição pela família.

No atendimento às famílias de crianças surdas no Centro de Estudos e Pesquisas em Reabilitação (CEPRE/FCM/ UNICAMP), ponto de referência deste estudo, nota-se que, no início, as mães questionam sobre o uso da língua de sinais, demonstram preocupação, ansiedade em relação à aprendizagem da fala e à integração do filho em uma sociedade ouvinte. Depois, à medida em que a família recebe informações sobre a abordagem do trabalho da instituição (Bilingüismo: aquisição da Língua de Sinais e da Língua Portuguesa), parece que algumas famílias permanecem no CEPRE pelo fato de acreditarem na Língua de Sinais, e outras, por observarem de alguma forma os progressos dos filhos.

$\mathrm{Na}$ literatura, observam-se duas concepções de surdez que se polarizam. Na primeira, conhecida como clínicoterapêutica, a surdez é vista como doença/déficit e o surdo como deficiente auditivo. Sendo assim, a pessoa surda necessita de um trabalho para suprir ou sanar essa falta e assim ser "curada". A "cura" está relacionada ao aprendizado da linguagem oral, ficando implícito que, quanto melhor a sua fala, melhor terá sido o processo de reabilitação da criança surda (Skliar, 1997), o que pressupõe o uso de aparelho de amplificação sonora e estimulação auditiva, por meio de treinamento auditivo e de fala.

Na segunda concepção, conhecida como sócio-antropológica, o termo "surdo" refere-se a qualquer pessoa que não escute, independentemente do grau da perda. A surdez é concebida como diferença e os surdos como "diferentes" dos ouvintes, sendo esta diferença decorrente, principalmente, da forma como os surdos têm acesso ao mundo, por meio da visão (Skliar, 1997).

Considerar a surdez uma diferença implica, entre outras coisas, respeitar a língua de sinais como a preferencial para o acesso ao conhecimento, sendo esta o elemento identificatório dos surdos. Expressas por meio da modali- dade visual-gestual, as línguas de sinais apresentam uma organização semelhante à observada nas línguas orais. Os surdos constituem-se em comunidades, compartilhando a mesma língua, valores culturais, hábitos e modos de socialização próprios. Assim, conseguem interagir cotidianamente em um processo comunicativo eficaz e eficiente (Skliar, 1997).

De acordo com a familiaridade que têm com a surdez, com as orientações recebidas dos profissionais que os atenderam e com a expectativa que constroem em relação aos filhos, os pais adotam, mesmo sem o saber, uma determinada concepção de surdez.

Se considerarem que os filhos devem falar, ou seja, usar a modalidade oral da Língua Portuguesa, os pais vão escolher uma instituição que priorize a linguagem falada como forma de comunicação dos e com os surdos. A recepção da linguagem pela criança surda se dará por meio da leitura oro-facial e da via auditiva (devidamente treinada), e a produção se dará pela fala, sendo os sinais geralmente proibidos.

Se, por outro lado, os pais optarem pelo uso de sinais, poderão escolher uma instituição como o CEPRE, na qual as crianças surdas são expostas à Língua de Sinais, na interação com adultos surdos e ouvintes que sinalizam, e à Língua Portuguesa, nas modalidades oral e escrita.

Hoje, no Brasil, há instituições e profissionais que adotam diferentes concepções de surdez e cabe aos pais, com o auxílio de profissionais habilitados, a escolha que esteja mais de acordo com a representação que têm da surdez.

Entendendo que a concepção de surdez que a família tem, em particular a mãe, vai responder não só pela escolha da instituição, mas também pela modalidade que será privilegiada na relação mãe-criança. É objetivo das autoras, neste trabalho, analisar a concepção que mães ouvintes têm da surdez e relacioná-la à modalidade de linguagem que será usada na interação.

\section{Método}

Este estudo se caracteriza como uma pesquisa qualitativa, na medida em que visa identificar as concepções que as mães constroem de seu filho surdo a partir da sua vivência na sociedade e dos sentidos construídos coletivamente a respeito da surdez e da pessoa surda.

\section{Participantes do estudo}

Os participantes do estudo foram 10 mães ouvintes e seus filhos surdos, que freqüentam atendimento especializado no CEPRE. Por ser uma pesquisa qualitativa, o número de participantes não foi previamente definido. $\mathrm{Na} 10^{\mathrm{a}}$ entrevista, verificou-se que alguns dados já estavam repetitivos e considerou-se que já havia um número suficiente para se alcançar os objetivos propostos para a pesquisa.

Todas as crianças selecionadas foram diagnosticadas como apresentando surdez severa ou profunda, sendo que quatro crianças apresentavam surdez devido à etiologia genética (Síndrome de Waanderburguer, Síndrome de Usher e alteração cromossômica), três devido à seqüela de prematuridade e intercorrências neonatais, duas por rubéola congênita 
e para uma criança, a etiologia era indefinida. Todas tinham mais de dois anos de seguimento no CEPRE.

As crianças-participantes foram agrupadas de acordo com a faixa etária: 3 a seis $6(1,2,5,7,9)$, que freqüentam pré-escola regular, e um outro grupo de crianças de 7 a 10 anos $(3,4,6,8,10)$, que freqüentam escola regular do ensino fundamental.

\section{Procedimentos}

Os dados foram obtidos por meio de entrevista com as mães, seguida de observações da criança surda em atendimento no CEPRE, após explicação do estudo e obtenção do consentimento livre e esclarecido, segundo Resolução 196/96 do Conselho Nacional da Saúde e aprovado pelo Comitê de Ética e Pesquisa da FCM/UNICAMP.

A entrevista foi semi-estruturada, gravada com equipamento de áudio-cassete, e composta dos seguintes tópicos principais: concepção sobre a surdez (como vê a surdez, como percebe as pessoas surdas); modalidade de linguagem (expectativa da mãe em relação à comunicação e modalidade de linguagem usada na interação mãe/criança).

As observações das crianças, gravadas em vídeo, foram efetuadas nas atividades em grupo com colegas surdos (no mínimo quatro vezes), o que possibilitou verificar a sua interação com um professor ouvinte e com um instrutor surdo.

Os tópicos observados nas interações da criança surda foram: modalidade de linguagem que utiliza (adapta a modalidade ao interlocutor ou usa a mesma modalidade independentemente do interlocutor).

\section{Análise dos dados}

Utilizou-se a técnica de análise de conteúdo, na qual a organização da análise é feita em torno de três pólos cronológicos: a pré-análise, a exploração do material e o tratamento dos resultados, que incluem a inferência e a interpretação (Bardin, 1977).

A análise empreendida foi do tipo temática e categorial (Bardin, 1977). Deu-se ênfase à categoria concepção de surdez e escolha da modalidade de linguagem, e procedeu-se à análise dos dados de cada mãe/criança em cada categoria, para depois se agruparem os dados das 10 mães e das 10 crianças nas duas categorias, o que possibilitou estabelecer a relação entre elas.

\section{Apresentação dos Dados e Discussão}

\section{Concepção de surdez e da pessoa surda}

Com o objetivo de possibilitar ao leitor articular a concepção que cada mãe entrevistada tem a respeito da surdez e da pessoa surda, optou-se por juntar os dados relativos aos dois temas para cada mãe e organizá-los de acordo com as semelhanças ou diferenças que os depoimentos apresentam.

Em relação à concepção de surdez, embora não se possa afirmar que as mães tenham conhecimento sobre as diferentes concepções geralmente atribuídas à surdez, é possível depreender, em suas entrevistas, idéias que as identificam com as concepções clínico-terapêutica ou sócio-antropológica.
$\mathrm{Na}$ análise sobre o que as 10 mães pensam a respeito da surdez, a maioria delas (M2, M3, M4, M5, M8, M9) revela considerar a surdez uma deficiência, embora nem todas utilizem esse termo.

A mãe 2, por exemplo, refere que a surdez é uma deficiência, no entanto procura atenuar a sua afirmativa, defendendo que a criança surda pode se tornar normal se for bem trabalhada, como se pode observar em suas palavras: " $E u$ acho que é uma deficiência, é, mas ela tem tudo se a criança for trabalhada, como a gente está buscando atendimento, ela está sendo atendida, ela pode vir a ser uma pessoa normal" (M2).

Com esta afirmativa, a mãe parece se filiar claramente à concepção clínico-terapêutica da surdez, segundo a qual, se for submetida a um bom trabalho de intervenção, particularmente de treino auditivo e de fala, a criança surda pode vir a ouvir e a falar, o que a tiraria da posição de deficiente e a tornaria mais próxima do normal.

Ao se referir às pessoas surdas, esta mãe, talvez na tentativa de valorizar a filha surda, ou para confirmar a idéia de que o trabalho pode tirar a criança surda da posição de deficiente, declara: "Eu acredito que, na inteligência, até supera os ouvintes, eu acho que eles são, no caso meu, a $G$, eu acho ela muito inteligente, eu acho ela mais inteligente que o $R$ (irmão), eu vejo assim o que as crianças da idade dela que é o ouvinte no caso (...) eu percebo porque ela é mais atenta, ela vê e fica atenta, porque ela não ouve, fica atenta aos olhos, olha tudo, observa tudo e traz a informação através dos olhos. Então na inteligência eu acho que eles superam os ouvintes" (M2).

Em seu relato, a mãe 2 atribui o fato de a criança ser atenta como sendo inteligente. Assim como os ouvintes, há surdos que prestam atenção e outros não. De modo geral, os surdos, por utilizarem a visão como principal via de acesso às informações, podem desenvolver melhor a atenção visual, mas é necessário que alguém interprete, por meio da linguagem, o que a criança vê para que ela possa aprender a atribuir sentido às "coisas" que vê.

Em outro trecho da entrevista, a mesma mãe acaba admitindo que, embora possam ser inteligentes, as crianças surdas precisam se esforçar mais para aprender, fato justificado pela falta de preparo dos professores ou por não ter uma escola especial para eles: "eu acredito que dificuldades tem, lógico que existe, porque eles têm que se esforçar mais, como na escola, por exemplo, porque eles vão na escola normal, é mais difícil, é difícil mesmo, porque até eles entenderem a divisão (...) divisão que já é difícil para uma criança que ouve, imagine um professor que não está preparado, que não tem como ele passar, então é difícil por esse motivo, por não ter um profissional capacitado para passar isso para a criança que está na idade escolar" (M2).

Esta mãe evidencia a representação que tem da filha com surdez, que, apesar de deficiente auditiva, é inteligente, capaz, sendo suas dificuldades acarretadas pelo fato do professor não conseguir ensinar.

Embora não se mostrem tão radicais, outras mães entrevistadas, como as M3, M4, M5, M8 e M9, parecem partilhar as mesmas concepções de surdez e de pessoa surda.

A mãe 3, por exemplo, parece evitar o termo "deficiência", substituindo-o por "problema". Sua posição, no entanto, 
é a mesma da mãe 2, como se pode observar na referência que faz à surdez. Segundo ela: "A surdez é um problema, mas não é porque é surdo que vai falar que é inválido. Tem como recuperar" (M3).

Nota-se, na fala desta mãe, hesitação em relação a como conceituar a surdez. Ela substitui o termo "deficiência", o qual parece estar revestido do sentido de "invalidez", por um menos carregado de preconceito, mas, mesmo assim, esclarece que a surdez não torna o surdo inválido, como que justificando o uso do termo.

Em relação às pessoas surdas, ela deixa transparecer a idéia de que a surdez, ou, como se detecta em suas palavras, a deficiência auditiva dificulta ou mesmo impede o aprendizado da criança. Ao se referir ao filho surdo, ela declara que: "Vai devagar, mas estão aprendendo um pouco, inclusive tem coisa que ele nem termina” (M3).

A imagem da surdez como deficiência pode ser observada em outro trecho da entrevista, em que a mesma mãe refere que os surdos são nervosos, o que, a seu ver, decorre do fato de não ouvirem direito, e exemplifica com o que acontece com o filho: "do aparelho quando a pilha acaba ele já sabe, por isso que eu falo que o nervosismo é por causa que não ouve. Ele fala 'D não está ouvindo nada, nada' e pega e joga a pilha fora. A pilha acabou mesmo e ele fica bravo" (M3).

Esta mãe parece atribuir à surdez as dificuldades do filho em aprender, assim como o nervosismo que apresenta.

Assim como a mãe 3, outras fizeram menção a aspectos comportamentais, como se fossem características das pessoas surdas. Algumas se referiram aos surdos como sendo meigos, carinhosos, nervosos, agressivos e agitados. Essa inconsistência nas características atribuídas aos surdos é endossada na literatura. Alguns autores caracterizam os surdos como agressivos, outros como submissos, bem como se encontram afirmações de que são igualmente explosivos e tímidos, teimosos e obedientes, desconfiados e confiantes, enfatizando-se aspectos considerados negativos (Lane, 1992). Como conseqüência destas afirmações, indivíduos surdos são rotulados, até pela própria família, como sendo nervosos, agressivos, agitados, como se estas características decorressem da surdez.

O mesmo questionamento em relação ao termo "deficiência", observado na fala da mãe 3, é encontrado também na entrevista da mãe 8. Segundo ela: “(...) talvez nem fosse uma deficiência, né. Porque parece que deficiência parece que a pessoa está impossibilitada de alguma coisa. E a surdez não parece ser assim, porque, convivendo com os surdos, assim, você vê que ele é muito esperto. De deficiente, assim, é muito pouco só porque não ouve mesmo (...) o que poderia ser falado assim (...) tem uma falha, talvez, sei lá” (M8).

Como a mãe 3, ela parece atribuir ao termo "deficiência" conotação de impossibilidade, incapacidade. No entanto, diferentemente daquela, acrescenta possibilidades compensatórias à surdez: ele é surdo, mas esperto. Para esta mãe, a esperteza é uma qualidade que valoriza a criança surda. É como se ela buscasse, com este atributo, mostrar que o filho não é deficiente.

Embora pareça se filiar à mesma concepção de surdez que as mães anteriores, a mãe 5 demonstra ter uma posição um pouco diferente em relação às qualidades das pessoas surdas. Segundo ela "eles são super inteligentes, até parece mais inteligente do que as crianças ouvintes mas é, não é por eles serem inteligentes que eles não vão ter dificuldades no aprendizado, claro que eles vão ter dificuldades, enquanto as outras crianças consegue associar a palavra ao som eles não vão conseguir fazer isso, então vão ter mais dificuldade no aprendizado sim” (M5).

Com esta afirmativa, a mãe parece, de certa forma, justificar as dificuldades dos surdos para aprender. Vale lembrar que seu filho está em escola regular e que, portanto, ela percebe que a falta da linguagem oral, ou mais precisamente da Língua Portuguesa na modalidade oral, causa realmente dificuldades na aprendizagem.

Uma posição diferente em relação à concepção de surdez é observada nas entrevistas de algumas mães, como as M1, M6, M7 e M10.

Algumas destas mães apresentam depoimentos ilustrativos do processo pelo qual passaram e do sentido que a palavra surdez foi assumindo para elas.

A mãe 1 confessa: "Eu não vejo mais como um problema, porque nossa era o fim do mundo (...) acho que a surdez, não é assim um bicho de sete cabeças, é difícil, mas é superável” (M1).

O termo "bicho de sete cabeças", usado por algumas mães nas entrevistas, parece significar algo muito complicado, difícil de lidar, mas não deficiente.

Como observado em outras entrevistas, esta mãe se refere ao filho para falar sobre como vê as pessoas surdas. Ela atribui, como outras mães, o desenvolvimento da criança surda à participação e ao incentivo da família. Refere: "Não sei se é porque tiveram mais incentivo, mais estímulo, eles se viram melhor, seja em sinais, seja em fala, seja no trabalho, e outros não, então depende muito do que a família oferece, do que a família incentiva, os caminhos que você leva" (M1).

A mesma mãe fala da sua experiência e das dúvidas que a acometeram em relação à capacidade do filho surdo. Segundo ela "Se você tem força de vontade nada é difícil, muita gente me vê na correria. Leva de manhã, vem para cá à tarde, (...) você tem que ter força de vontade, porque se você não tiver, você não vai conseguir nada. Eu sei que eles, pelo menos a $K$, ela desenvolveu muito bem, muito bem mesmo, porque eu achei que ela não ia conseguir". (M1)

Posição semelhante pode ser observada na entrevista da mãe 6, que afirma: "Hoje eu vejo de jeito mais natural, não é mais bicho de sete cabeças, é uma coisa natural (...) particularmente eu não gosto desse termo deficiente, é uma palavra pesada para eles e eles não são isso, a gente fala deficiente uma pessoa que é incapaz, uma coisa muito pesada (...) eu prefiro falar que é surdo e ponto né, não ficar prolongando, porque eles são capazes de tudo" (M6).

Esta mãe parece sintetizar o que, nas entrevistas de outras mães, já foi apontado, isto é, que o termo "deficiente" tem conotação pejorativa, de incapacidade física (invalidez) ou mesmo mental.

Embora se perceba, principalmente nas falas das mães 1 e 6, o uso do termo surdez e surdo, é na entrevista da mãe 10 que se nota uma posição bastante definida em relação à surdez e à pessoa surda.

O depoimento desta mãe, embora se assemelhe, em muitos aspectos, ao de outras mães entrevistadas, ilustra a concepção de surdez como diferença e do filho surdo, como 
diferente e capaz. Ela relata: "Antes parecia que surdo tinha um padrão. Sabe assim, surdo é assim, normalmente faz isso. Hoje, eu não vejo assim. Mas, assim a B é surda, como os surdos devem ser, só que ela tem uma diferença tão grande, assim, porque ela é minha filha. Então surdo ou não, eu vou educar ela do meu jeito, entendeu? Assim, é uma pessoa, (...) dá para ser educada, compreensiva, os valores (...) sabe acho que tem que ensinar. É diferente? É diferente, eu não tenho outro filho, eu não sei como é ensinar um ouvinte, eu ensino a $B$, através da Língua de Sinais, falando com ela (...) Não encaro como deficiente (...) Não esqueço que ela é surda nenhum momento, sabe. Se ela está de costas, tenho o maior respeito por ela. Eu acho isso o fundamental. Assim, eu vejo a surdez só como, tem que usar outra língua com eles. Então assim, mas eu acho que é capaz de tudo, criança surda, pessoa surda" (M10).

Como outras mães, ela atribui à família a responsabilidade pelo sucesso da criança surda. Diz: "Eu tenho, assim, a plena consciência, assim, tenho a plena certeza que o pai ou a mãe podem fazer a diferença na vida de um filho, seja surdo ou não (...) desde pequenininha, assim, principalmente os atendimentos para mim, assim, as minhas orientações eu acho que foi a base (...) se eu tiver orientação aqui, mas chegar em casa e não fizer nada, não vai adiantar (...) Não depende se é pai ou mãe, avó, avô, não sei. Acho que faz diferença de como que você vai lidar com a criança" (M10).

Depreende-se, nesta fala, a importância das orientações que recebeu dos profissionais, o que, para ela, é o que vai fazer a diferença no desenvolvimento da criança.

\section{Modalidade de linguagem escolhida na interação mãe-criança}

Como já foi referido anteriormente, a escolha da modalidade de linguagem que será privilegiada na interação mãe ouvinte-criança surda vai depender do conhecimento que a família tem da surdez e da expectativa que constrói em relação ao filho surdo.

Pelo fato de ser ouvinte, é esperado que, inicialmente, a família, em particular a mãe, privilegie a fala, forma habitual de interação na sociedade ouvinte. No entanto, à medida que a interação vai acontecendo, a representação que a mãe vai fazendo das potencialidades lingüísticas do seu filho vai determinar a modalidade que será usada na interação com o filho, se oral ou gestual.

Pereira (1989) analisou a interação entre mães ouvintes e crianças surdas, que estavam matriculadas em uma instituição que privilegiava a linguagem oral, e constatou que, apesar da orientação recebida, todas as mães usavam gestos e fala com os filhos, sendo as diferenças observadas entre as duplas atribuídas, pela autora, à representação que cada parceiro ia construindo do outro enquanto interlocutor. Cada uma das quatro mães observadas tendeu a privilegiar a modalidade interativa correspondente à representação que tinha da surdez e das potencialidades lingüísticas do filho surdo.

Tendo em vista o objetivo deste estudo, foram retirados das entrevistas dados que permitissem relacionar as concepções de surdez e de pessoa surda que as mães demonstram ter, com a modalidade de linguagem que elas pensam ser a melhor para seu filho e para os surdos em geral.
Vale lembrar que a instituição onde foi realizado este estudo expõe as crianças surdas à Língua de Sinais e à Língua Portuguesa, nas modalidades oral e escrita, e oferece curso de Língua de Sinais para os pais e familiares.

A maioria das mães (M1, M2, M4, M5, M6, M7, M8, M9, M10) refere que o melhor para o surdo seria usar os sinais e a fala: "Para início sem sombra de dúvida que é a linguagem de sinais, para o início é fundamental porque eu lembro que quando K era pequena, eu não falava nada para ela, (...) eu pegava dava banho, eu trocava, sem falar para onde vai, o que vai fazer, o que vai acontecer. Então, se não fosse os sinais, como eu ia explicar para ela, agora já quando eles já estão maiores, aí sim, a linguagem oral também é importante" (M1).

No depoimento da mãe 1, os gestos, ou mesmo os sinais, parecem ser admitidos como formas provisórias de comunicação, enquanto as crianças não dispõem de outra modalidade.

Como a mãe 1, a maioria das outras mães das crianças pré-escolares (M2, M7, M9) referiu que seus filhos usam predominantemente os sinais: "em casa, é mais sinais".

Para estas mães, o uso dos sinais pode decorrer da falta de conhecimento do português. Para elas, parece que a representação é de que a surdez do filho e a pouca idade o deixam sem recursos para desenvolver uma comunicação oral. Assim, a mãe usa os sinais e insiste em que o filho os use.

A mãe 7 enfatiza que os surdos, assim como os estrangeiros, devem usar a língua que lhes é mais acessível, no caso dos surdos a de sinais: "com a linguagem dos sinais, é o correto (...) não acho que eles têm que falar. Quando os estrangeiros vêm aqui, não é obrigatório ter que falar a nossa língua, só os que realmente querem aprender, não acho assim que tem que falar, sabe, não acho. Se conseguir falar, graças a Deus, amém, melhor ainda para ela, senão não vou você tem, você tem, porque isso aí acaba se tornando uma obsessão, você acaba até atrapalhando alguma coisa na vida da criança" (M7).

Embora, à primeira vista, esta mãe pareça estar defendendo o direito dos surdos de usar a Língua de Sinais, a expressão "Se conseguir falar, graças a Deus, amém, melhor ainda para ela" deixa transparecer uma descrença em relação às possibilidades linguísticas das pessoas surdas. Por outro lado, critica os que insistem em que os surdos devam falar.

Diferentemente das outras mães de crianças pré-escolares, a M5 afirma que seu filho utiliza em casa a fala e o sinal: "ele faz assim igual quando ele quer brincar de alguma coisa, ele faz assim a bicicleta (faz o sinal) (...) ele não fala bicicleta, ele fala 'cadê mãe' (e faz o sinal), acho que é difícil falar bicicleta sabe, quando ele está vendo os livrinhos dele, ele sabe qual é o cachorro, qual é o leão, ele faz assim (sinal) às vezes nem faz, mas produz o som, faz 'aarr', (...) fala e faz assim, a maioria das coisas que ele consegue falar bem, porque ele sabe o sinal, porque ele fala e faz o sinal de cachorro, faz as duas coisas". Ela também fala e usa sinais: "às vezes falo e faço sinal, às vezes eu só falo (...) depende do que a gente vai falar, igual quando eu falo, 'apaga a luz para mamãe', ele apaga a luz, eu não preciso fazer o sinal, não sei se ele já entende o som do que eu quero, ele já faz, sem eu pedir, agora se a gente está lá na cozinha e eu quero que ele desligue a televisão aí eu tenho que falar 'desliga a 
televisão’ (em sinal) e ele vai lá na sala e desliga, porque se eu falo 'desliga a televisão', ele vai e abre a geladeira, eu falo 'não, vai lá desliga a televisão', daí ele vai e faz," (M5). Esta é a forma de comunicação que os dois parecem usar habitualmente.

No caso desta criança menor, o fato de ter um resíduo auditivo melhor foi interpretado pela mãe como a criança podendo ouvir, e, assim, a perda de audição não impossibilitaria o desenvolvimento da comunicação oral. Dessa forma, a mãe parece ter construído uma imagem do filho como tendo condições de falar e privilegia a fala na interação com ele, utilizando os sinais apenas quando ele não entende a fala.

A representação dessa mãe, de que a perda de audição não impossibilita o desenvolvimento da comunicação oral pelo surdo, é semelhante às de outras mães, como a M4, a M6 e a M10, no entanto a diferença é que estas últimas parecem não usar os sinais como uma forma provisória de comunicação.

A expectativa de que a melhor forma do surdo se comunicar é por intermédio dos sinais e da fala aparece no depoimento da mãe 10. No entanto, segundo suas palavras, isto pode ser muito difícil para as crianças surdas: "É o sinal, eu acho que, nós ouvintes tem que usar os dois com eles. Mas eu acho que eles usar os dois é difícil, é muito difícil (...) eu acho que não pode privar os surdos da fala, não assim, eu acho que tem que dar os dois, se ele conseguir os dois, tudo bem, se ele não conseguir também. Então eu acho que não pode privar eles 'não, é surdo, então só sinal'. Não, eu não acho certo, eu acho que tem que oferecer ao surdo, agora, se ele vai colher os dois, acho que vai de cada um. Mas eu acho que os dois, o bilingüe, é o ideal" (M10).

Esta mãe, que, na análise das concepções de surdez, havia demonstrado uma visão diferente em relação à surdez e ao filho surdo, defende que os ouvintes usem as duas modalidades, cabendo à criança surda fazer uso daquela que melhor corresponder à representação que faz de suas habilidades lingüísticas ou das de seu interlocutor. Ela deixa transparecer o seu desejo de que a criança surda seja bilíngüe, isto é, que possa usar a Língua de Sinais e a Língua Portuguesa para interagir com surdos e ouvintes.

Ainda em relação ao uso da fala e dos sinais, a mãe 10 refere: "nossa, ela tá usando muita fala, precisa ver que gracinha, é, esses dias, eu ligo para ela sempre do serviço para casa, oito horas, ela sabe o horário que eu ligo, que éo horário que eu janto, né. Então, uma vez ela atendeu e o pai dela saiu e falou: 'a mamãe vai ligar oito horas?' Então ela virou e falou assim 'Oi mãe, eu te amo, beijo, o papai não ta, tá bom' e desligou, porque ela sabia que era eu. Daí esses dias acabou a força lá do serviço e eu liguei mais cedo, sete horas, porque eu tava avisando que provavelmente a gente ia embora, porque não tava voltando a força. E ela atendeu, o M. não tava lá, porque quando o M. tá, às vezes ela fala 'papai' e dá para ele né? Daí, uma gracinha, ela falou assim no telefone 'oi, tudo bom? Ai, eu não tô entendendo porque eu sou surda, tá bom? O papai não tá' e desligou. Eu achei, assim, tão linda, ela se expressa, assim, sabe? Ela não tem nenhum preconceito de dizer que ela não tá entendendo, que ela é surda" (M10).

Apesar desta mãe admitir que a criança surda possa se comunicar por meio de sinais, é visível a sua satisfação ao relatar os progressos da filha na linguagem oral. No entanto, apesar de ela referir que a filha está conseguindo usar a Língua Portuguesa na modalidade oral, afirma que, em casa, a língua de base continua sendo a de Sinais. Ela refere: "quando eu quero explicar alguma coisa, nossa, é só sinal, coisa nova, assim, conceito, é só sinal (...) Ela pergunta muito, e ela só sossega quando ela tem entendimento. Quando ela entendeu ela 'ah, tá bom'” (M10).

No depoimento dessa mãe, percebe-se que, quando a criança se sente valorizada, compreendida, ela apresenta um bom auto-conceito e, assim, não há problema algum em dizer que ela é surda. Pode-se dizer que esta criança está em um processo de formação de sua identidade surda (Perlin, 1998) e tornou-se bilíngüe, correspondendo à representação que a mãe tem de suas potencialidades lingüísticas.

Assim como a mãe 10, outras mães das crianças escolares (M4, M6) referem que as crianças usam a fala e os sinais, e, mesmo com surdez profunda, usam a oralidade. Apesar de reconhecerem a surdez do filho, não representam essa perda de audição como uma impossibilidade de desenvolvimento da modalidade oral. Parece que, na medida em que as crianças vão crescendo, por estarem maiores, teriam adquirido mais recursos para poder se comunicar nas duas línguas, de Sinais e Portuguesa. Assim, na interação com os filhos, as mães relatam que se valem de recursos orais e dos sinais para se comunicar e se ajustam à representação que vão construindo das possibilidades comunicativas do filho: "antes era só sinais, hoje é mais a fala, mas também tem sinais (...) ela mesmo já falou pra mim que não quer que faça mais sinais, mas não tem como, ela mesma acaba falando por sinais e eu também, não tem como, em casa teve uma época que só falava e ela falava 'faz com a mão mãe, fala com a mão', então quando a gente estava fazendo sinais ela 'fala, fala com a boca', então teve essa convivência assim e se hoje ela não entende, que eu percebo que ela não entende, eu faço sinal, ou então ensino na fala quando é um sinal que eu não sei" (M6). No mesmo trecho da entrevista, é possível observar a representação que a criança parece estar construindo das suas potencialidades lingüísticas.

Diferentemente, a mãe 8 , ao perceber a dificuldade da filha em usar a fala, enfatiza a importância de o surdo desenvolver uma boa leitura oro-facial, além dos sinais: “conseguir passar o que eles estão falando, é por sinais ou escrita (...) a fala eu acho que é meio difícil, assim, pra tá falando sem ouvir (...) mas a leitura labial eu acho que é muito importante. Seria o ideal. Seria leitura labial e sinais" (M8). A mãe refere que sua filha usa predominantemente os sinais em casa: "Sinais e até gestos, e agora está tentando escrever também. Às vezes quando ela quer falar alguma coisa que eu não entendo ela quer escrever, ou quer saber como que escreve" (M8). O fato de a mãe admitir que algumas vezes não entende a filha, demonstra que tanto ela como a filha, não dominam suficientemente a Língua de Sinais. Apesar de referir que usa sinais, parece usá-los como suporte para facilitar a comunicação, ou seja, como modalidade da Língua Portuguesa. É interessante notar que essa criança freqüenta o CEPRE desde os 3 anos, e está sendo exposta à Língua de Sinais na instituição há sete anos, mas parece que a mãe fala com a filha, e usa gestos ou sinais ao invés de usar a Língua de Sinais, e a menina, por sua vez, parece tentar corresponder à representação de falante, ainda que a 
sua fala não seja compreendida pela mãe. O predomínio da fala e de gestos e sinais em casa parece ter contribuído para a dificuldade apresentada pela criança em adquirir a Língua de Sinais, e, agora, com 10 anos, parece estar instituindo uma outra forma de comunicação com a mãe, a escrita, pelo fato de se tratar de uma modalidade da Língua Portuguesa mais acessível visualmente.

Nos atendimentos em grupo, observou-se a maneira da criança comunicar-se, tornando difícil a compreensão por parte do interlocutor, até mesmo quando este é o instrutor surdo, que a questiona várias vezes, tentando entender o que ela está expressando, como o faz com as crianças menores que estão em processo de aquisição da Língua de Sinais.

Diferentemente de todas as mães, a 3 refere que a melhor forma para o surdo se comunicar é por meio da fala e explica: “(...) é porque é mais fácil, o sinal é muito difícil” (M3). A mãe deixa claro que tem muita dificuldade em aprender os sinais, apesar de estar no CEPRE há mais de três anos. Como seu filho apresenta comunicação através da oralidade, ela não sente necessidade de aprender a usar a Língua de Sinais. A mãe refere que usa só a linguagem oral em casa: "aumenta, ele manda para eu aumentar, o que eu falo ele não entende, ele fala 'aumenta', para eu falar mais alto". Quando é a mãe que não entende o que o filho fala, ela refere: "às vezes quando ele fala alguma coisa que eu não entendo, daí ele faz o sinal", e explica "se caso ele falar comigo eu sei, mas me comunicar mesmo usando em sinais com ele, não" (M3).

Nas observações realizadas nos atendimentos, pode-se observar que a criança 3 fala com o colega surdo quando este está de costas ou fala com o adulto surdo, mas sabe alguns sinais quando o instrutor surdo pede para ele fazer, embora não os use constantemente. Parece que a criança construiu um modelo de comunicação de ouvinte, isto é, para falar não precisa olhar, falando com os colegas surdos mesmo eles estando de costas, mas precisa olhar para o interlocutor quando este usa sinais.

\section{Paralelo entre concepção de surdez que as mães demonstram ter e modalidade de linguagem privilegiada na interação}

Após analisar as concepções de surdez e de surdos que cada mãe revela nas entrevistas e da modalidade que elas parecem privilegiar na interação, procedeu-se ao estabelecimento de um paralelo, buscando relacionar as duas categorias.

Observou-se que, entre as mães (M2, M3, M4, M5, M8, M9) que revelam ter uma representação da surdez como deficiência, somente uma delas (M3) refere que a melhor forma do surdo se comunicar é por meio da modalidade oral.

Ao referirem que a surdez é uma deficiência e que as crianças surdas precisam de um trabalho para poder se tornar "normais" é de se esperar que as mães valorizem a comunicação por meio da fala. No entanto, todas referem que os surdos precisam utilizar os sinais e a fala, embora, em seus depoimentos, se perceba que algumas privilegiam a fala, como a mãe 5 , e, outras privilegiam os sinais, como a mãe 2 .

A mãe 5, apesar de ter uma representação da surdez como deficiência, afirma que os surdos são inteligentes, mas têm dificuldades no aprendizado. Como tem essa visão reparadora da surdez, justifica o predomínio do uso da modalidade oral da Língua Portuguesa com o filho, pois, aprendendo a falar, torna-se menos deficiente. Ao referir que são inteligentes, parece atribuir a esta qualidade, o aprendizado da fala. No entanto, nota-se uma contradição, quando diz que os surdos são inteligentes, mas têm dificuldades. Esta forma de se referir aos surdos pode ser tomada como decorrência da representação que a mãe tem de surdez, uma vez que a visão de deficiência traz embutida a visão de incapacidade e, assim, os surdos, apesar de serem inteligentes e conseguirem falar, terão mais dificuldades em aprender.

Já a mãe 2 também demonstra ter uma concepção de surdez como deficiência, na medida em que afirma que o trabalho de reabilitação pode melhorar a vida do surdo e ele pode vir a tornar-se uma pessoa normal. Seria de se esperar que ela privilegiasse a fala, já que é assim que o surdo poderia deixar de ser deficiente. No entanto, a mãe refere que seria melhor para o surdo usar os sinais e a fala, e, por enquanto, a filha usa predominantemente os sinais. Parece que a mãe usa sinais porque sua filha é pequena e não conta ainda com recursos orais para se comunicar e, assim, o uso dos sinais parece ser transitório, apenas para facilitar a comunicação entre elas.

As outras mães (M1, M6, M7, M10), que revelaram não conceber a surdez como deficiência, também mencionaram a importância das duas línguas (de Sinais e Língua Portuguesa). Contudo uma delas, a de número 7, prioriza os sinais. Faz-se importante considerar que a criança da mãe 7 é pequena e, portanto, não dispõe de muitos recursos orais para se comunicar, por isso parece priorizar os sinais.

$\mathrm{Na}$ relação entre concepção de surdez e modalidade de linguagem, percebe-se que, tanto as mães que têm uma concepção mais clínica da surdez, como as que não a encaram como deficiência, mencionam a importância do surdo adquirir as duas línguas.

Como os pais são ouvintes, parece ser natural que tenham a expectativa de que seus filhos sejam bilíngües para poder conviver tanto com o grupo de surdos, como com o grupo de ouvintes, já que é a minoria de ouvintes que aprende a Língua de Sinais. No entanto, vale lembrar que, pelo fato de freqüentarem o CEPRE, que segue uma abordagem bilíngüe, essas mães receberam orientações sobre a importância e a necessidade do uso da Língua de Sinais, o que pode ter contribuído para que elas percebessem que a criança pode se desenvolver melhor se utilizar a Língua de Sinais e que esta não impede ou atrapalha o desenvolvimento da fala. Apesar de todas terem a mesma orientação, percebem-se diferenças na ênfase que as mães dão à modalidade de língua. $\mathrm{O}$ quanto a mãe privilegia uma modalidade em detrimento da outra vai depender da concepção que ela tem de surdez e da representação que construiu das possibilidades lingüísticas do seu filho surdo.

É importante ressaltar que, por vezes, a relação entre a concepção de surdez e a escolha da modalidade é influenciada pelas opções que os pais têm à sua disposição na comunidade em que estão inseridos.

Verificou-se que, das 10 mães, somente duas delas apresentaram posições mais definidas e opostas em relação à concepção de surdez e da pessoa surda. Uma delas, a M10 parece se aproximar de uma concepção sócio-antropológica 
da surdez, na medida em que concebe o surdo como diferente, aceita a Língua de Sinais e não esquece em nenhum momento que a filha é surda. Prioriza a via visuo-gestual para a criança ter acesso às informações e conhecimento de mundo. Essa mãe optou pelo trabalho bilíngüe e a filha, em idade escolar (9 anos), usa as duas línguas, a de Sinais e a Portuguesa, dependendo do seu interlocutor.

A mãe 3 revela, em seus depoimentos, se identificar com uma concepção clínico-terapêutica da surdez, acreditando que tanto o aparelho auditivo quanto a fala trazem a cura para a perda da audição. Apesar de freqüentar o CEPRE, relata que não consegue aprender a Língua de Sinais e o filho entende tudo pela fala. O filho, em idade escolar ( 7 anos e 8 meses), faz uso constante do aparelho auditivo, ficando "nervoso", quando a pilha acaba. Ele apresenta uma fala inteligível, mais para pessoas que estão acostumadas a ouvir a voz de surdos, e usa assistematicamente os sinais com os colegas surdos no CEPRE.

\section{Considerações Finais}

A expectativa da família ouvinte é geralmente que seu filho possa usar a Língua de Sinais entre os surdos e a Língua Portuguesa na modalidade oral com os ouvintes. A fala possibilitaria a integração dos filhos no mundo dos ouvintes e os sinais, por outro lado, a melhor compreensão e o estabelecimento de relações sociais entre iguais.

As mães não se mostram muito seguras em relação à sua concepção de surdez. Parecem hesitar em usar o termo deficiência, por ter uma conotação pejorativa, mas suas palavras refletem que têm a visão de que o surdo é menos capaz.

Como a maioria das mães não está ciente da concepção que tem de surdez, sua representação das possibilidades lingüísticas do filho surdo parece variar de acordo com as informações que elas vão tendo sobre a surdez e com a vivência com outras pessoas surdas, o que parece explicar o fato de, em alguns momentos, privilegiarem os sinais, e, em outros, a fala.

Fica evidente a importância de a família ter uma concepção mais clara da surdez para que possa escolher de forma mais segura a modalidade de linguagem que será privilegiada na relação mãe-criança.

Cabe ressaltar a importância de que não só as famílias, mas os profissionais da área da saúde, da educação e os próprios membros da sociedade, possam refletir sobre suas concepções para que atitudes preconceituosas e ações discriminatórias em relação à pessoa surda se modifiquem e que o surdo possa, de fato, ser incluído numa sociedade majoritária, tendo o direito de ser reconhecido e respeitado na sua diferença.

\section{Referências}

Bardin, L. (1977). Análise de conteúdo. Lisboa: Edições 70.

Behares, L. E. (1993). Nuevas corrientes en la educación del sordo: de los enfoques clínicos a los culturales. Cadernos de Educação Especial da Universidade Federal de Santa Maria, 1(4), 20-53.

Corde - Coordenadoria Nacional para Integração da Pessoa Portadora de Deficiência. (1996). Mídia e Deficiências: Manual de Estilo.

Eleweke, C. J. \& Rodda, M. (2000). Factors contributing to parents' selection of a communication mode to use with their deaf children. American Annals of the Deaf, 145(4), 375-383.

Figueira, E. (1996). Imagem e conceito social da deficiência (quarta parte). Temas sobre Desenvolvimento, 27, 39-41.

Goffman, E. (1978). Estigma: notas sobre a manipulação da identidade deteriorada (2.ed.). Rio de Janeiro: Zahar Editores.

IBGE - Fundação Instituto Brasileiro de Geografia e Estatística (2006). Censo demográfico. Retirado em 03/03/2006 do http:// www.ibge.gov.br .

Lane, H. (1992). A máscara da benevolência: a comunidade surda amordaçada. Lisboa: Instituto Piaget.

Lima, M. C. M. P. (1997). Avaliação de fala de lactentes no período pré-linguístico: uma proposta para triagem de problemas auditivos. Tese de Doutorado, Universidade Estadual de Campinas, Campinas.

Pereira, M. C. C. (1989). Interação e construção do sistema gestual em crianças deficientes auditivas, filhas de pais ouvintes. Tese de Doutorado, Universidade Estadual de Campinas, Campinas.

Perlin, G. T. T. (1998). Identidades surdas. Em C.Skliar (Org.), A surdez: um olhar sobre as diferenças (pp. 51-73). Porto Alegre: Editora Mediação.

Skliar, C. (1997). Uma perspectiva sócio-histórica sobre a psicologia e a educação dos surdos. Em C. Skliar (Org.), Educação e exclusão: abordagens sócio-antropológicas em educação especial (pp. 105-153). Porto Alegre: Mediação.

Recebido em 25.08.2006

Primeira decisão editorial em 30.10.2007

Versão final em 21.12.06

Aceito em 28.03.2007 